\title{
An Unusual Cause of Low Back Pain
}

LUKAS A. HOLZER, MD; ANDREAS LEITHNER, MD, Department of Orthopedic Surgery, Medical University of Graz, Graz, Austria. Address correspondence to Dr. L.A. Holzer, Department of Orthopaedic Surgery, Medical University of Graz, Auenbruggerplatz 5 , 8036 Graz, Austria.

E-mail: lukas.holzer@medunigraz.at. J Rheumatol 2015;42:549-50; doi:10.3899/jrheum.140788

Cotton gauzes are commonly used during surgical procedures. Retained surgical gauzes can result in tumors called textiloma.

A 63-year-old female patient presented with chronic low back pain that had lasted about 20 years. She had surgery in the lumbar spine for discus herniation 19 years ago, as well as surgery for an intramuscular lipoma in the right lumbosacral paravertebral muscles 16 years ago. Clinically, she had pain in the right lumbosacral paravertebral region. There were neither signs of inflammation nor neurological deficit.

The T1-weighted, fat-suppressed, gadolinium-enhanced magnetic resonance imaging (MRI) in axial plane showed a mass of a maximum size of $3.5 \mathrm{~cm}$ in diameter in the right paravertebral muscles with central necrosis and an enhanced hyperintense rim (Figure 1). An open biopsy was performed showing a well-capsulated mass consisting of fibers that imposed macroscopically as cotton tissue. A frozen section was performed that showed granulomatous tissue with foreign body reaction. The whole mass was resected, presenting multiple pieces of tissue compatible with a textiloma resulting from the lipoma resection (Figure 2).

Textiloma is defined as a tumor composed of cotton matrix or synthetic fibers surrounded by granulomatous reactions resulting from forgotten surgical gauzes ${ }^{1}$. Cotton gauzes are commonly used to achieve hemostasis during surgical procedures, such as dissection for discus herniation ${ }^{2}$. Precautions are taken during surgery to avoid leaving

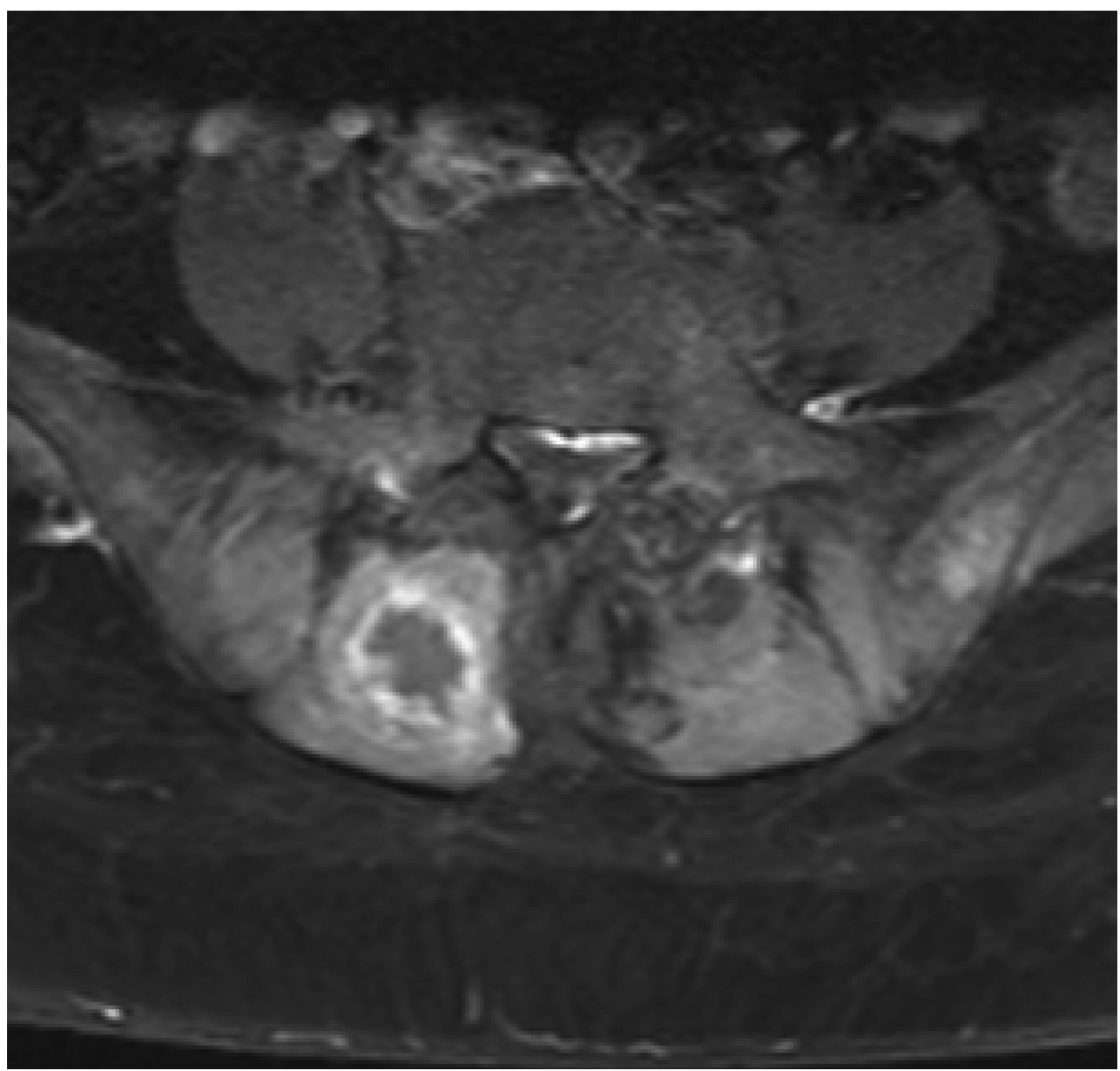

Figure 1. MRI in axial plane showing a mass of a maximum size of $3.5 \mathrm{~cm}$ in diameter in the right paravertebral muscles with central necrosis and an enhanced hyperintense rim after contrast medium injection. MRI: magnetic resonance imaging.

\section{Personal non-commercial use only. The Journal of Rheumatology Copyright (c) 2015. All rights reserved.}




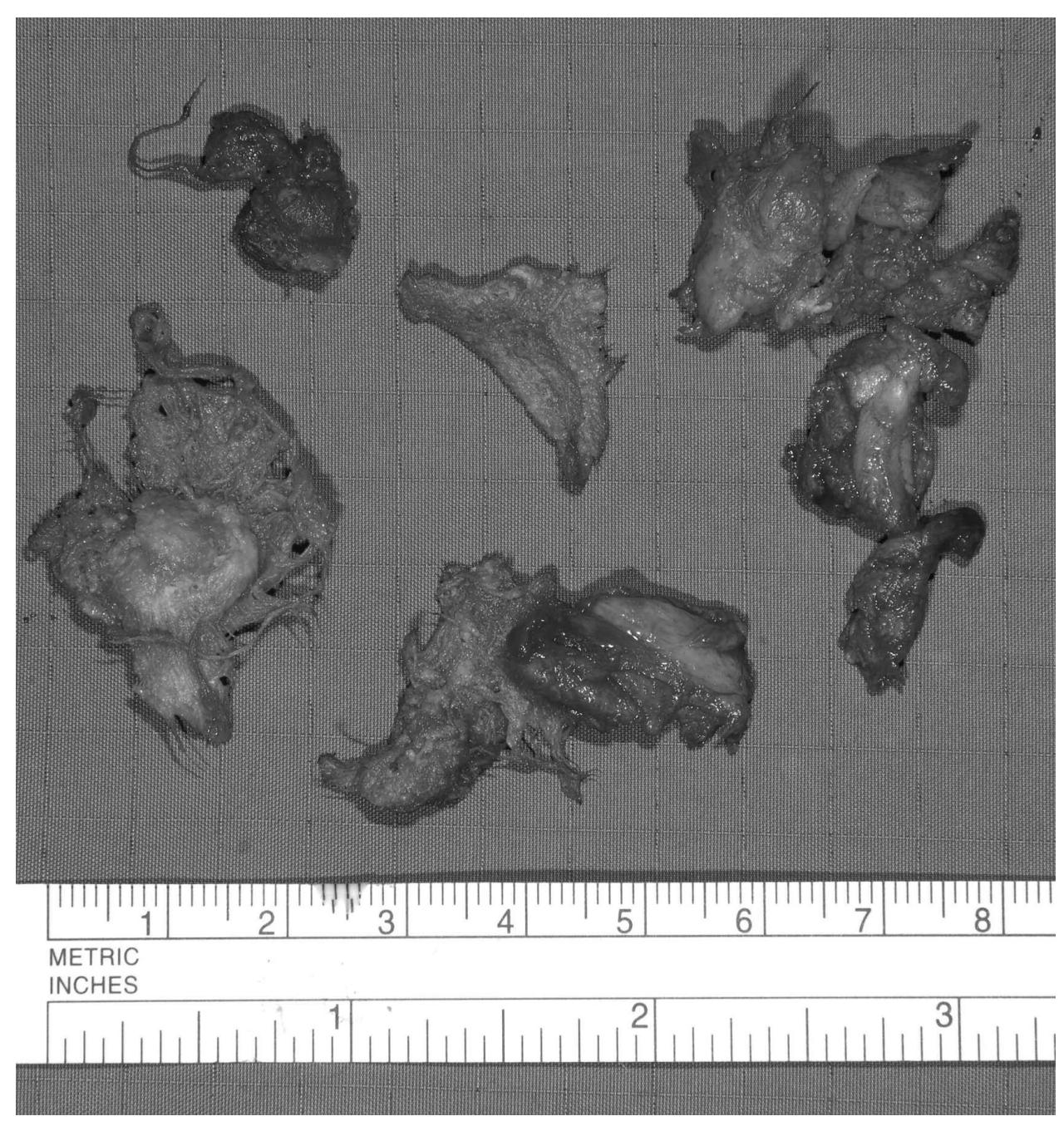

Figure 2. Pieces of tissue compatible with a textiloma.

such materials behind. However, mistakes do happen and the consequences of such retained foreign bodies can vary clinically or radiologically. Early symptoms of these retained materials after surgery are infections or abscess formation. Some of these, however, remain clinically asymptomatic for many years and only later cause a foreign body reaction in the surrounding tissue, indicating significant mass effect ${ }^{3}$. MRI can accurately identify foreign body masses; however, their appearance can differ greatly ${ }^{4}$.

\section{REFERENCES}

1. Aydogan M, Mirzanli C, Ganiyusufoglu K, Tezer M, Ozturk I. A 13-year-old textiloma (gossypiboma) after discectomy for lumbar disc herniation: a case report and review of the literature. Spine J 2007;7:618-21.

2. Gifford RR, Plaut MR, McLeary RD. Retained surgical sponge following laminectomy. JAMA 1973;223:1040.

3. Gawande AA, Studdert DM, Orav EJ, Brennan TA, Zinner MJ. Risk factors for retained instruments and sponges after surgery. N Engl J Med 2003;348:229-35.

4. Van Goethem JW, Parizel PM, Perdieus D, Hermans P, de Moor J. MR and CT imaging of paraspinal textiloma (gossypiboma).

J Comput Assist Tomogr 1991;15:1000-3. 